\title{
Enhanced Oil Recovery of the Anisotropic Reservoir
}

\author{
Zakirov S., Piscarev V. \\ Oil and Gas Research Institute, \\ Academy of Sciences, Russia
}

\begin{abstract}
Copyright 1995, Steering Committee of the European IOR - Symposium.
This paper was presented at the 8th. European IOR - Symposium in Vienna, Austria, May 16 - 17, 1995

This paper was selected for presentation by the Steering Committee, following review of information contained in an abstract submitted by the author(s). The paper, as presented has not been reviewed by the Steering Committee.
\end{abstract}

\begin{abstract}
Usually, productive formations of oil and gas fields are anisotropic on their reservoir properties. Most scientists paid attention to determination and taking into consideration the anisotropy of permeability in vertical direction. Theoretical studies and real data confirm that such type of anisotropy renders the significant influence on the development processes of oil and gas fields. But attention to take into account the lateral anisotropy is not enough. Therefore in this paper the attempt is made to consider the influence of lateral anisotropy on the indices of the oil displacement under water flooding at different well pattern and their configurations.
\end{abstract}

\section{INTRODUCTION}

For a long time the geological investigations show the fact of anisotropy of the reservoir properties in productive formations. In particular it concerns carbonate rocks ${ }^{1,2}$.

There are a lot of publications which take into account the anisotropy of reservoir properties in vertical direction. Especially it concerns the papers which consider the oil and gas inflow problems for wells with partial penetration, the formation of gas and water cones $^{3-5}$. Approximate solution for system of the vertical wells in anisotropic reservoir could be found in work ${ }^{6}$ as applied to the steady-state flow regime.

In connection with wide application of the horizontal wells in practice of oil and gas production, some solutions ${ }^{7.9}$ for horizontal well draining the anisotropic reservoir were obtained and pointed the ways of taking into consideration the formation anisotropy in numerical simulation of the horizontal well ${ }^{10}$. Of course, the analytical solutions deal with single-phase flow.

Some publications consider that there are reasons to improve several ideas of multiphase flow theory in anisotropic reservoirs ${ }^{11-14}$.

Thus, there are the different consumers of information on the reservoir anisotropy. It needs not only qualitative, but also quantitative data about anisotropy. Therefore different methods were worked out to determine the formation anisotropy both in vertical direction $^{15-17}$ and along productive area ${ }^{16,18}$. Besides, the injection of some indicators is used in order to estimate parameters of the lateral anisotropy ${ }^{19,20}$.

At the same time taking into account the anisotropy in processes of displacing one fluid by another is needed investigations. It's evident that the lateral anisotropy should affect the injection and producing well pattern, the water-cut dynamics and the ultimate oil recovery factor(ORF).

The configuration of injection and producing well pattern, well pattern density are the subject of the steadfast studies long ago. It's connected with their influence on ORF and the expenses for the recovery of oil resources. There are a lot of publications on the clearing of ORF dependance from the configuration of well pattern and well pattern density ${ }^{3,21-28}$. As authors know, the preceding investigations concerned, basically, the cases of isotropic reservoir or they took into account 
the different types of heterogeneity, wedging out of bed and so on. In the present paper the processes of oil displäcement by working agents are considered as applied to the anisotropic reservoir, and the corresponding comparison with isotropic formations is given. Very interesting results are observed under the well pattern deformation both in isotropic and anisotropic reservoirs.

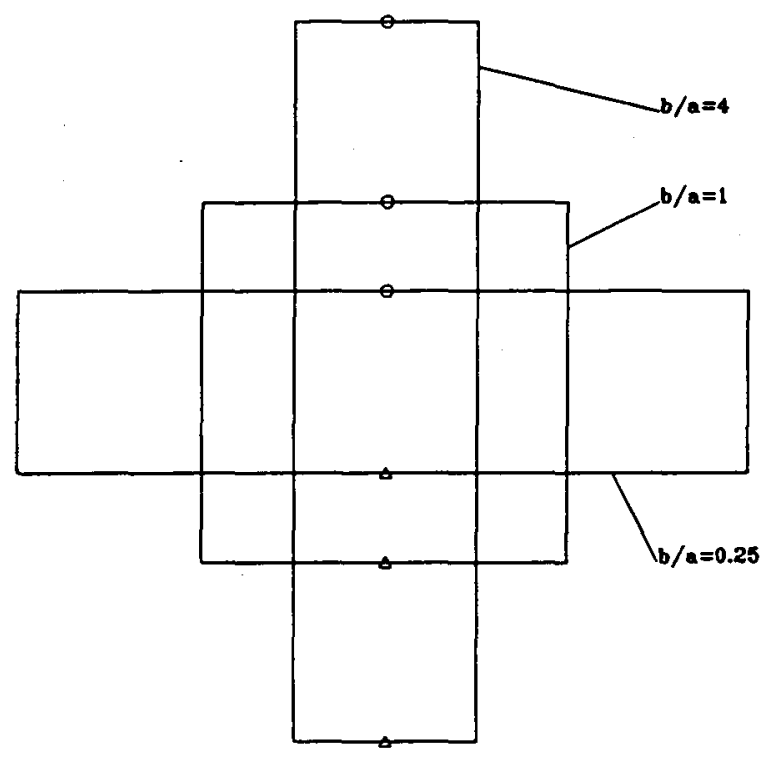

Fig. 1. Example of linear well system deformation.

\section{PROBLEM STATEMENT}

The regularities and quantitative characteristics of the one fluid by another displacement processes are examined under different lateral anisotropy and various configurations of the considered well patterns.

In this connection the oil by water displacement processes are investigated for two characteristic well pattern - linear and five-spot well system. Probably, some well patterns, such as seven-spot well system, nine-spot well system and so on, are not useful in the anisotropic formation since some of the operating wells appear under unfavourable conditions from the viewpoint of premature water cutting.

It's supposed that the main axes of the permeability tensor are directed along $O x$ and $O y$ axes respectively. Permeability along $O x$ axis is denoted by $\mathrm{Kx}$ and along $\mathrm{Oy}$ axis - Ky. Investigations are fulfilled for different $\mathrm{Kx} / \mathrm{Ky}$ ratios. Comparisons are given for the cases when $\mathrm{Kx} / \mathrm{Ky}=1 ; 10 ; 100$. In the case of the five-spot well system the obtained results for the mentioned $\mathrm{Kx} / \mathrm{Ky}$ ratios are correct also for the cases when $\mathrm{Ky} / \mathrm{Kx}=10 ; 100$ since we have symmetry of flow scheme. In the case of linear well system we have to consider the mentioned cases of $\mathrm{Ky} / \mathrm{Kx}$ ratios separately.

Three variants differed by phase permeability and mobility ratio are examined. In the first variant the phase permeabilities are linear function of saturation.
This case is of interest as applied to miscible displacement processes. In the second variant the phase permeabilities are polynomial relations of saturation. Herewith water gets mobility at saturation equal to 0.25 , and residual oil saturation is equal to 0.23 . In the third variant the phase permeabilities are taken as quadratic relations of saturation starting from the coordinate beginning and from the point with water saturation equal to 1 , accordingly to water and oil.

Absolute value of permeability is uniform and equal to $0.2 \mathrm{D}$ in the cases with isotropic formation. In the case of anisotropic reservoir this permeability value is minimum of two main values of permeability tensor. We will not become confused by high permeability values $\mathrm{Ky}$ as sometimes permeability attains $10 \mathrm{D}$, for example, in the case of North Sea fields. Porosity and formation thickness are taken the same in all variants and equal to 0.2 and $15 \mathrm{~m}$ respectively.

In the first and second series of variants the mobility ratio is equal to 1 and oil viscosity in formation conditions - $3.64 \mathrm{mPa}$. Therefore, for instance, thickened water could be considered as injected fluid. In the third series of variants the unfavourable case is studied when the mobility ratio of oil and displacing agent is equal to 10 . At the same oil viscosity the viscosity of injected agent is equal to $0.364 \mathrm{mPa}$ s that corresponds to water in formation conditions: initial formation pressure is equal to $15.2 \mathrm{MPa}$ and formation temperature $-65^{\circ} \mathrm{C}$.

In the case of linear well pattern the basic variant is characterized by the equal distance between wells in rows and between rows. This distance is $500 \mathrm{~m}$. Basic five-spot well pattern also has equal sides. They are $1000 \mathrm{~m}$.

The well pattern density is not changed in all cases of linear and five-spot well systems. But well pattern deformation is carried out by the change of the sides' ratio(see fig. 1). The oil rate of the operating well and the injection rate of well are constant in all considered variants and equal to $100 \mathrm{~m}^{3} /$ day.

The parameter for comparison of considering variants is not obvious. Evidently, the considering variants will be characterized by various development duration, different water-cut dynamics and ORF. Frequently they want to get back as soon as possible the used up capital charges since oil production. From this connection the current ORF at 50\% wells' water-cutting is of some interest. As applied to offshore fields the 70\% water-cutting is rather critical because of limited opportunities to treat the water cut production. Usually oil production is made until $98 \%$ water-cutting at onshore fields. Therefore at the outset we will analyze the development figures under achievement of 50\% water-cutting. Then the analysis is completed by results for cases of water-cutting at $70 \%$ and $98 \%$.

Stated below results are obtained with use of $2 \mathrm{D}$ two-phase numerical simulator. Herewith new solving algorithm of respective problem is employed which provides less numerical dispersion as compared with 

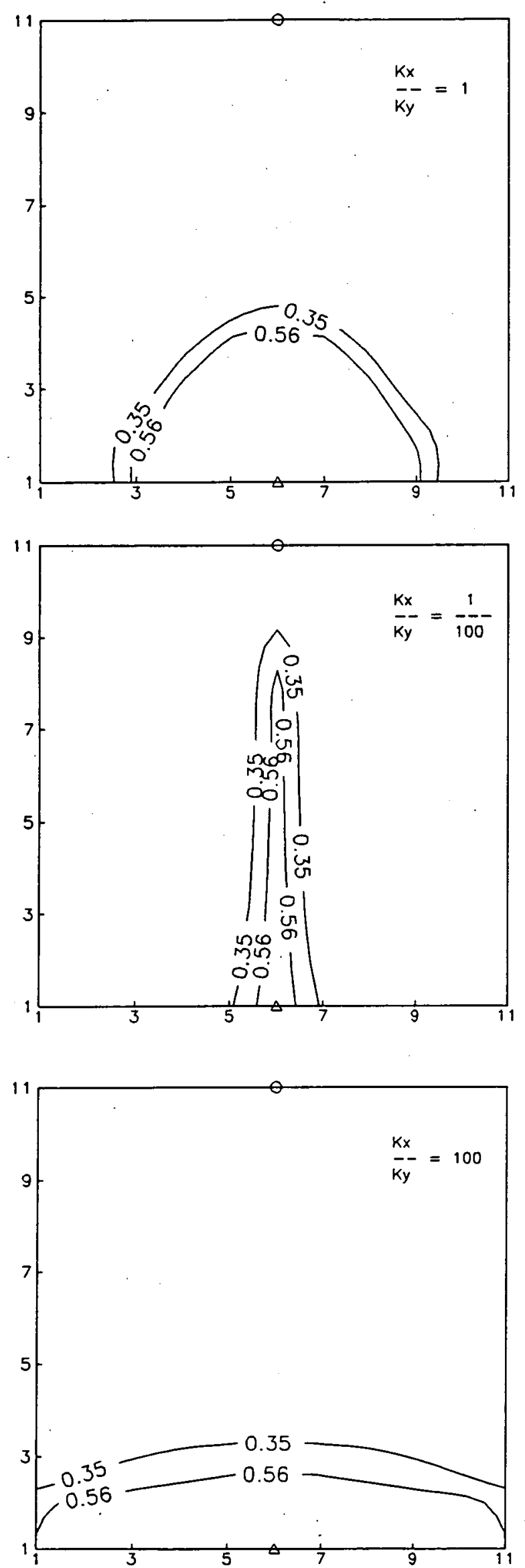

Fig. 2. Isolines of water saturation under oil-by-water displacement in II variant. another methods ${ }^{29}$.

\section{LINEAR WELL PATTERN}

Considering formation element is oriented in this case so that the producing and injection wells are disposed at $\mathrm{Oy}$ axis and displacement takes place upwards(see fig. 1). Here and far the following indices achieved at the moment of $50 \%$ water-cutting deserve the most attention: - oil recovery factor;

- pressure difference $\Delta P$ between grid points where the operating and injection wells are located;

- development duration $T$ when mentioned watercut takes place.

Calculation results for linear well pattern are given in table I when distance between wells and rows is equal to $500 * 500 \mathrm{~m}$. First of all it's noted that the difference in development indices in cases of isotropic and anisotropic formations is explained by various character of phase permeability in corresponding variants.

Table 1. Development indices for linear well pattern.

\begin{tabular}{|c|c|c|c|c|c|c|}
\hline \multirow{2}{*}{\multicolumn{2}{|c|}{ Variants }} & \multicolumn{5}{|c|}{ Anisotropy parameter, $\mathrm{Kx} / \mathrm{Ky}$} \\
\hline & & \multirow{2}{*}{$\frac{100}{.9271}$} & \multirow{2}{*}{$\begin{array}{c}10 \\
.8937\end{array}$} & \multirow{2}{*}{$\frac{1}{.7110}$} & \multirow{2}{*}{$\frac{1 / 10}{.3132}$} & \multirow{2}{*}{$\frac{1 / 100}{.1117}$} \\
\hline 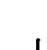 & ORF & & & & & \\
\hline & $\triangle \mathrm{P}, \mathrm{MP}$ & 0.72 & 0.95 & 1.62 & 0.36 & 0.06 \\
\hline & T,days & 7320 & 7170 & 6020 & 2890 & 870 \\
\hline \multirow{3}{*}{ II } & ORF & .6600 & .6504 & .5675 & .2483 & .0818 \\
\hline & $\triangle \mathrm{P}, \mathrm{MPz}$ & 3.98 & 4.85 & 7.6 & 1.7 & 0.34 \\
\hline & $\mathbf{T}, \mathrm{days}$ & 5000 & 4940 & 4480 & 2080 & 620 \\
\hline \multirow{3}{*}{ III } & ORF & .6385 & .6090 & .5255 & .2332 & .0934 \\
\hline & $\triangle P_{1}, M_{2}$ & 0.15 & 0.18 & 0.32 & 0.07 & 0.012 \\
\hline & $\mathbf{r}, \mathrm{day}$ & 7850 & 7310 & 6900 & 3070 & 1040 \\
\hline
\end{tabular}

Analysis of table 1 allows to remark very strong dependance of considered development indices from formation anisotropy degree.

It's obviously that if the most permeable direction coincides with displacement direction then ORF sharply decreases by growth of $\mathrm{Ky} / \mathrm{Kx}$ ratio. So, for example, in variant I the ORF, which equals to 0.7110 in the case of isotropic formation, reduces to 0.3132 and 0.1117 at $\mathrm{Ky} / \mathrm{Kx}=10$ and 100 respectively. Naturally, the development duration $\mathrm{T}$ and pressure loss $\Delta \mathrm{P}$ are shortened.

The correct taking into consideration of formation anisotropy by well disposing leads to considerable increase of ORF. In the same variant if displacement is organized along direction with the less permeability then ORF grows up from 0.7110 to 0.8937 and 0.9271 accordingly when $\mathrm{Kx} / \mathrm{Ky}=10$ and 100 . It's explained by that the displacement front is complicated by water 
fingering in considerable less degree as compared with the case of isotropic formation. This circumstance is coniniected with that injected fluid is of favourable condition for spread in direction along Ox axis. Therefore the possibility of forming the stagnant zones is decreased. Here the growth of development durations
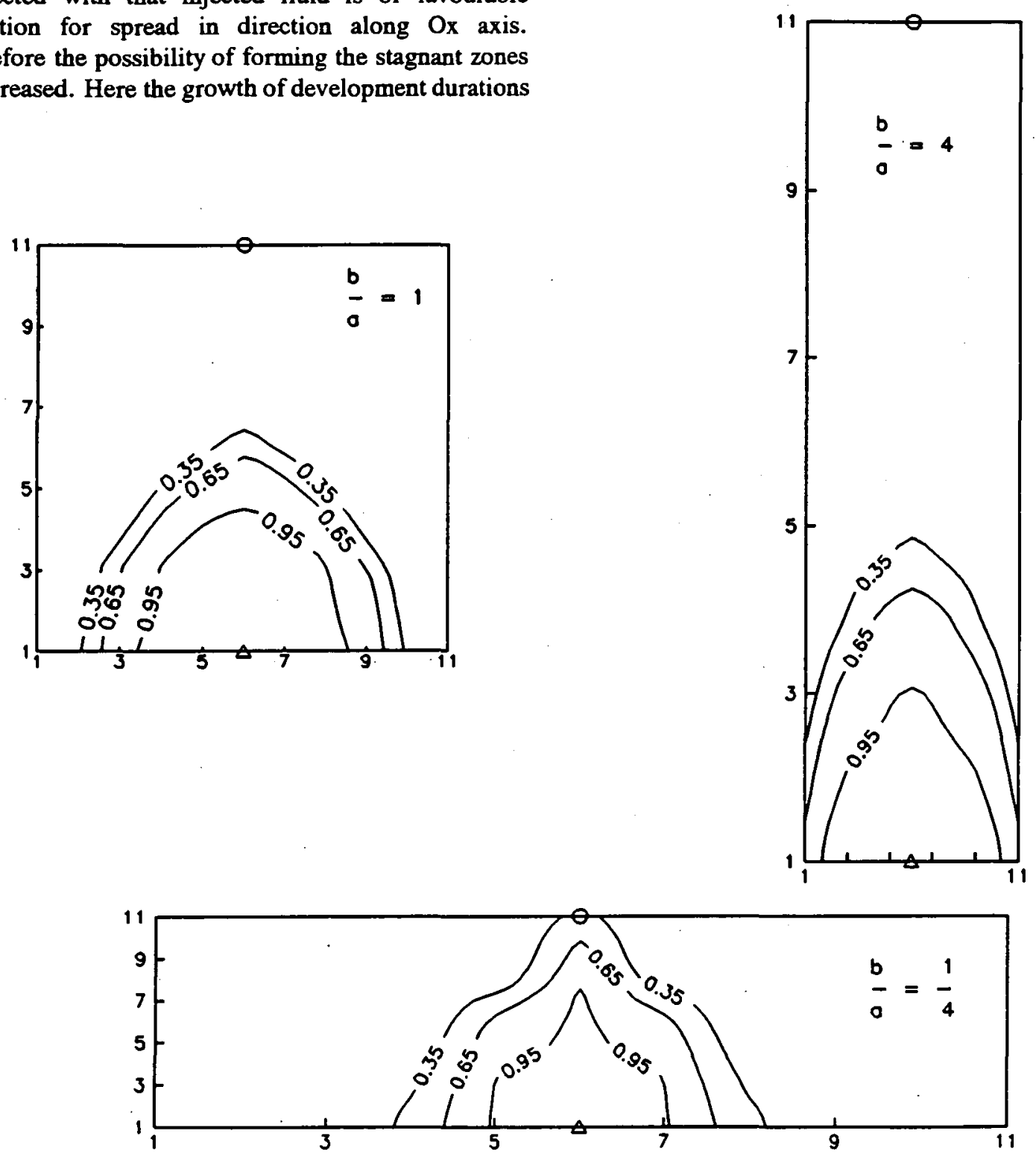

Fig. 3. Isolines of water saturation in deformed linear well patterns at the same time in II variant.

takes place due to more ORF succeed in corresponding subvariants. It's important that energetic losses are reduced as well. It's explained by the pressure losses $\Delta \mathrm{P}$ decrease due to high permeability along direction which coincides with direction of main axis of permeability tensor with the most main value. Calculation results for II and III variants are explained by the same way. Low pressure losses $\Delta \mathrm{P}$ in III variant are connected with that the injected fluid viscosity is less by 10 times in comparison with II variant. The given in table $1 \Delta \mathrm{P}$ values correspond to ultimate time T.

Figure 2 allows to understand the flow process peculiarities in considered both isotropic and anisotropic reservoirs and the obtained numerical indices too. Here isolines of water saturation, as applied to II variant, are presented at the same date for cases when $\mathrm{Kx} / \mathrm{Ky}=1$; 100 and $1 / 100$ respectively. Evidently, fig. 2 does not need additional explanations as it illustrates properly the said above statements.

It's revealed in the course of present studies that the well pattern deformation can render considerable influence on the development indices as well as the formation anisotropy. Let's deform the considered development element, namely will change the ratio of sides b/a from 1 to 4 or $1 / 4$ as applied to isotropic 
formation(see fig. 1). Here and far a - length of element side along $O x$ axis, $b$ - along Oy axis. Calculation results are given in table 2 for these cases.

Table 2. Development indices under different well pattern deformations.

\begin{tabular}{|c|c|c|c|c||}
\hline \multirow{2}{*}{ Variants } & \multicolumn{3}{|c||}{ Ratio of sides, b/a } \\
\cline { 2 - 5 } & 1 & 4 & $1 / 4$ \\
\hline \multirow{3}{*}{$\mathrm{O}$} & $\mathrm{ORF}$ & 0.7110 & 0.9065 & 0.2574 \\
\cline { 2 - 5 } & $\Delta \mathrm{P}, \mathrm{MP}$ & 1.62 & 3.3 & 1.05 \\
\hline \multirow{2}{*}{$\mathrm{O}$} & $\mathrm{ORF}$ & 0.5675 & 0.6540 & 0.2150 \\
\cline { 2 - 5 } & $\Delta \mathrm{P}, \mathrm{MPa}$ & 7.6 & 18.25 & 5.0 \\
\hline \multirow{3}{*}{$\mathrm{m}$} & $\mathrm{ORF}$ & 0.5255 & 0.6175 & 0.1904 \\
\cline { 2 - 5 } & $\Delta \mathrm{P}, \mathrm{MP}$ & 0.32 & 0.77 & 0.21 \\
\hline
\end{tabular}

The case, when $b / a=1 / 4$, does not deserve any attention. It's presented only to emphasize the role and meaning of the well pattern deformation factor. The case, when $b / a=4$, shows it's useful to reduce distance between wells into row and to increase distance between rows, having the same number of wells (at invariable well pattern density). The increase of distance between operating and injection wells is favourable for growing of ORF. Herewith the energetic expenses increase in such cases. For example, $\Delta \mathrm{P}$ value enlarges from $1.62 \mathrm{MPa}$ to $3.3 \mathrm{MPa}$ in I variant.

Figure 3 permits to trace the influence of well pattern deformation factor on sweep efficiency. Here the isolines of water saturation are presented at the same time, as example, for the II variant. We can see that larger productive area is embraced by displacement process at $b / a=4$.

Dependencies of the well water-cut and ORF from time are given at fig. 4 and 5 for different formation anisotropy degree in the case of linear well pattern when $b / a=1$. These dependencies show that the formation anisotropy is the important factor and it predetermines all peculiarities of water-cut and ORF values.

We can't say that the deformation problem of development element is new. For example, it's spoken about in work ${ }^{38}$. But there the author doesn't feel the required assurance in such matter as the stretching of well pattern at fixed $\Delta P$ leads to reduction of oil rate. Unlike the work ${ }^{28}$ the fulfilled investigations show more exactly the expediency of well pattern deformation. As a result the ORF could be increased, the same oil rates could be kept under the growth of $\Delta P$ value, i. e. the growth of energetic expenses.

There is a need to give some numbers in order to feel really with what well spacing we would deal in the course of deformation of initial development element with $500 * 500 \mathrm{~m}$ size. At the invariable well pattern density the side $a$ is equal to $250 \mathrm{~m}$ and side $b$

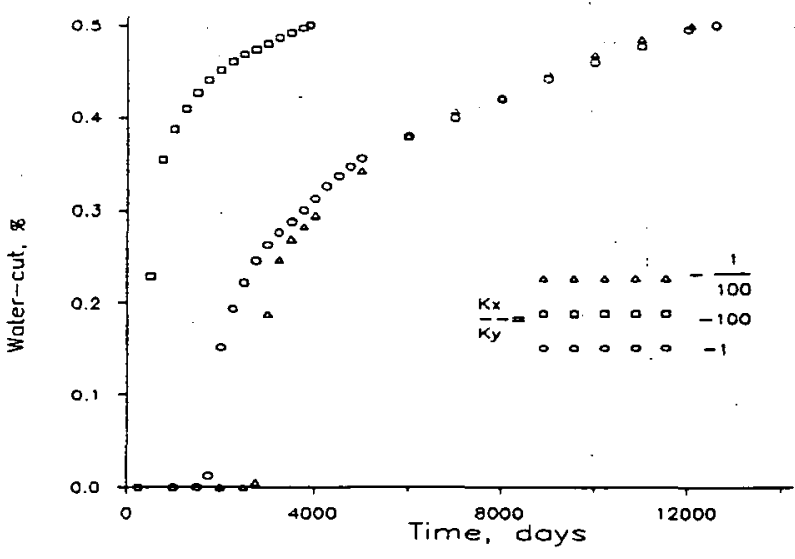

Fig. 4. Water-cut dynamics in the case of linear well pattern.

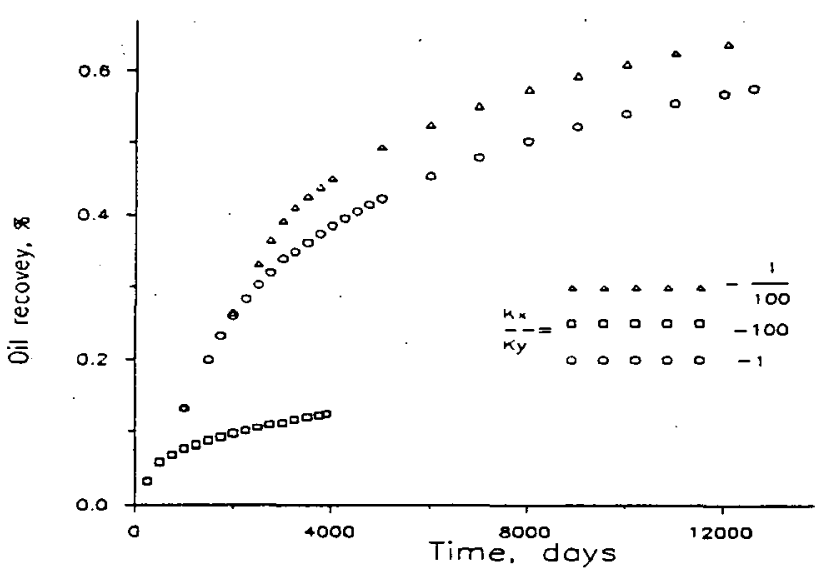

Fig. 5. ORF dynamics at different formation anisotropy in the case of linear well pattern.

is equal to $1000 \mathrm{~m}$ when the ratio of sides is equal to $1 / 4$. When the ratio of sides $b / a=16$, we have $a=125 \mathrm{~m}$, $\mathrm{b}=2000 \mathrm{~m}$. Probably such stretching of development element sides would be very useful in the cases of offshore field mastering since it would allow to increase the distance between platforms and might reduce their number.

\section{FIVE-SPOT WELL PATTERN}

Calculation results for isotropic and anisotropic formations as applied to five-spot well system are presented in table 3 . Besides, the data of table 3 reflect the influence of well pattern deformation factor on the development indices.

Let's consider at first results obtained for isotropic formation as they represent an independent interest.

1. In the case of isotropic reservoir the symmetrical results take place as applied to the stretching of the five-spot well pattern along $O x$ axis or Oy axis.

2. The stretching of examined well pattern is 

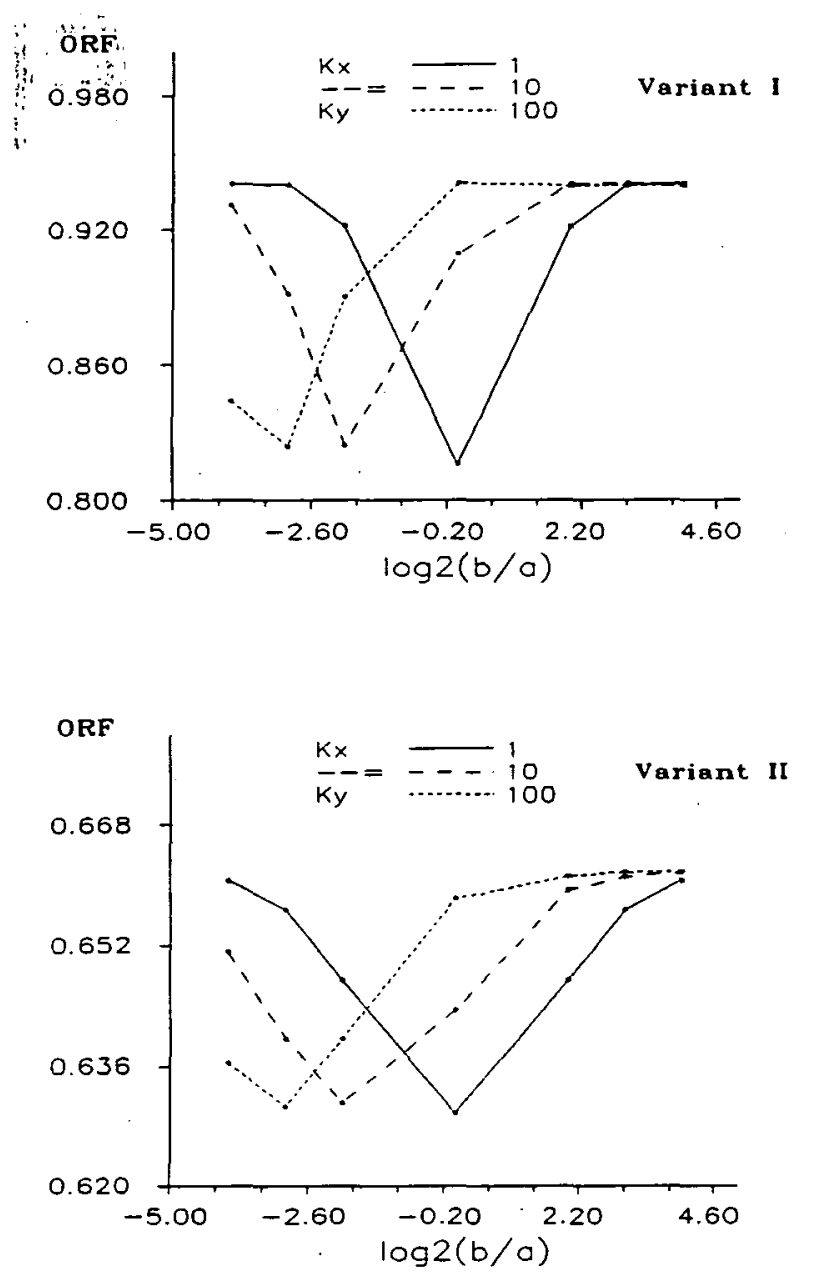

Fig. 6. ORF as a function of sides' ratio of five-spot pattern.

favourable for $O R F$ in the I variant of phase permeabilities and mobilities. ORF increases from 0.8161 to $0.9214,0.9399$ and 0.9404 respectively when the ratio of sides b/a is changed from 1 to 4,8 and 16 . Here we can see that the well pattern deformation factor acts irregularly. Thus, the greatest ORF growth takes place at increasing the ratio of sides from 1 to 4 . Like the previous case moving of the producing well away from the injection one leads to increase of pressure losses $\Delta P$ between wells and to increase of duration $T$ of displacement process. Nevertheless it's obvious that well pattern deformation could be effective method. For example, ORF increases from 0.8161 to 0.9214 by enlarge of sides' ratio b/a from 1 to 4 and pressure losses $\triangle \mathrm{P}$ growth from $3.25 \mathrm{MPa}$ to $4.3 \mathrm{MPa}$. In a word the determination of optimal well pattern deformation degree is both technical and economical problem.

It's deserved to be underlined the constant dependence of ORF growth from well pattern deformation degree in II variant. Besides ORF increase the reduction of development time is achieved in III variant.

3. Formation anisotropy, when $b / a=1$, acts positively on ORF in the considering five-spot well system orientation case relatively to the main axes of permeability tensor. In the series of first(I) variants ORF increases from 0.8161 to 0.9094 and 0.9407 by growth of $\mathrm{Kx} / \mathrm{Ky}$ to 10 and 100 respectively. In second(II) series of variants we have sequentially values of $O R F$ equal to $0.6297,0.6434,0.6582$. In third(III) variants we have the analogous tendency in figures $-0.6214,0.6333$, 0.6392 .

4. In the case of anisotropic formation the considering dependencies of ORF from well pattern deformation character differ by new peculiarities. If the well pattern deformation is made in direction, where $\mathbf{b} / \mathbf{a}<1$, it results in significant $\mathrm{ORF}$ decrease. For instance, in I variant, when $\mathrm{Kx} / \mathrm{Ky}=10$, ORF reduces from 0.9094 at $b / a=1$ to 0.8244 at $b / a=1 / 4$. But $O R F$ at $b / a=1 / 16$ reaches 0.9311 . When $\mathrm{Kx} / \mathrm{Ky}=100$, the minimum value of $O R F$ is occurred at $b / a=1 / 8$ : $O R F$ decreases from 0.9407 to 0.8240 . Some dependencies of ORF from well pattern deformation character are given in fig. 6. They testify that in each particular case the well pattern both in isotropic and anisotropic reservoir demands more careful investigations. Herewith the fivespot well pattern should be stretched in direction with the smallest permeability, though some growth of energetic expenses ( $\triangle \mathrm{P}$ value) takes place.

\section{ORF - WATER-CUTTING}

The criterion of production water-cutting influences on conclusions following from simulation data. Some of the calculation results of ORF under different water-cutting given in the fig. 7-9 confirm this idea in case of fivespot well pattern.

The mentioned above figures allow to express the fairly important practical conclusion. Under considerable output water-cutting $(\mathbf{9 8 \%}$ ) the five-spot well pattern is small sensitive to

- possible their deformation, i. e. it is no need of any stretching;

- degree of formation anisotropy.

These conclusions as applied to large watercutting are fair when direction of that well pattern coincides with main axes of permeability tensor. If diagonal connecting producer and injector coincides with one of permeability tensor axes the conclusions mentioned above for linear well system are becoming just to considered well pattern.

\section{CONCLUSIONS}

1. Formation anisotropy renders the large influence on the indices of the process of oil displacement by different agents. Incorrect taking into account of formation anisotropy could lead to sharp reduce of ORF. By correct taking into consideration of reservoir anisotropy one could achieve the ORF increase as compared with the case of isotropic reservoir.

2. The well pattern deformation factor provides 
Table 3. ORF values for five-spot well pattern at different phase permeabilities, mobilities, anisotropy and the ratio of element sides.

\begin{tabular}{|c|c|c|c|c|c|c|c|c|}
\hline \multicolumn{2}{|c|}{ Variants } & \multicolumn{7}{|c|}{ Ratio of sides, b/a } \\
\hline & & $1 / 16$ & $1 / 8$ & $1 / 4$ & 1 & 4 & 8 & 16 \\
\hline . & . & & & sotropy 1 & leter, $\mathrm{Kx}$ & & & \\
\hline \multirow{3}{*}{ I } & ORF & .9413 & .9402 & .9222 & .8168 & .9222 & .9402 & .9413 \\
\hline & $\Delta \mathrm{P}, \mathrm{MPa}$ & 11.7 & 6.57 & 4.32 & 3.24 & 4.32 & 6.57 & 11.7 \\
\hline & T,days & 7350 & 7350 & 7260 & 6540 & 7260 & 7350 & $7350^{\circ}$ \\
\hline \multirow{3}{*}{ II } & ORF & .6645 & .6584 & .6491 & .6305 & .6491 & .6584 & .6645 \\
\hline & $\Delta \mathrm{P}, \mathrm{MPa}$ & 64.8 & 36.7 & 23.9 & 19.0 & 23.9 & 36.7 & 64.8 \\
\hline & T,days & 5050 & 5000 & 4930 & 4770 & 4930 & 5000 & 5050 \\
\hline \multirow{3}{*}{ III } & ORF & .4165 & .4162 & .4129 & .3840 & .4129 & .4162 & .4165 \\
\hline & $\Delta \mathrm{P}, \mathbf{M P a}$ & 5.58 & 3.10 & 2.02 & 1.56 & 2.02 & 3.10 & 5.58 \\
\hline & T.days & 3300 & 3320 & 3330 & 3110 & 3330 & 3320 & 3300 \\
\hline \multicolumn{9}{|c|}{ Anisotropy parameter, $\mathrm{Kx} / \mathrm{Ky}=10$} \\
\hline \multirow{3}{*}{ I } & ORF & .9316 & .8921 & .8249 & .9102 & .9413 & .9403 & .9402 \\
\hline & $\triangle P, M P a$ & 1.54 & 1.16 & 1.03 & 1.24 & 3 & 5.7 & 11.2 \\
\hline & T,days & 7305 & 7080 & 6615 & 7200 & 7350 & 7335 & 7335 \\
\hline \multirow{3}{*}{ II } & ORF & .6543 & .6399 & .6318 & .6451 & .6637 & .6623 & .6642 \\
\hline & $\Delta P, M P a$ & 8.55 & 6.22 & 6.04 & 6.88 & 16.5 & 31.2 & 61.2 \\
\hline & T.days & 4935 & 4840 & 4780 & 4900 & 5050 & 5020 & 5040 \\
\hline \multirow{3}{*}{ III } & ORF & .4156 & .4069 & .3874 & .4010 & .4163 & .4170 & .4171 \\
\hline & $\triangle P, M P a$ & 0.724 & 0.548 & 0.496 & 0.583 & 1.43 & 2.72 & 5.37 \\
\hline & T,days & 3340 & 3310 & 3150 & 3320 & 3300 & 3300 & 3300 \\
\hline \multicolumn{9}{|c|}{ Anisotropy parameter, $\mathrm{Kx} / \mathrm{Ky}=100$} \\
\hline \multirow{3}{*}{ I } & ORF & .8443 & .8245 & .8905 & .9409 & .9403 & .9402 & .9402 \\
\hline & $\triangle \mathrm{P}, \mathrm{MPa}$ & 0.334 & 0.326 & 0.364 & 0.78 & 2.8 & 5.6 & 11.17 \\
\hline & T,days & 6750 & 6615 & 7065 & 7350 & 7335 & 7335 & 7335 \\
\hline \multirow{3}{*}{ II } & ORF & .6372 & .6318 & .6399 & .6607 & .6633 & .6643 & .6646 \\
\hline & $\triangle \mathrm{P}, \mathrm{MPa}$ & 1.96 & 1.9 & 1.96 & 4.34 & 15.3 & 30.4 & 61.7 \\
\hline & T,days & 4820 & 4780 & 4840 & 5020 & 5030 & 5040 & 5040 \\
\hline \multirow{3}{*}{ III } & ORF & .3925 & .3873 & .4067 & .4163 & .4172 & .4172 & .4172 \\
\hline & $\triangle P, M P a$ & 0.160 & 0.157 & 0.172 & 0.369 & 1.34 & 2.67 & 5.33 \\
\hline & T.days & 3190 & 3150 & 3310 & 3310 & 3300 & 3300 & 3300 \\
\hline
\end{tabular}




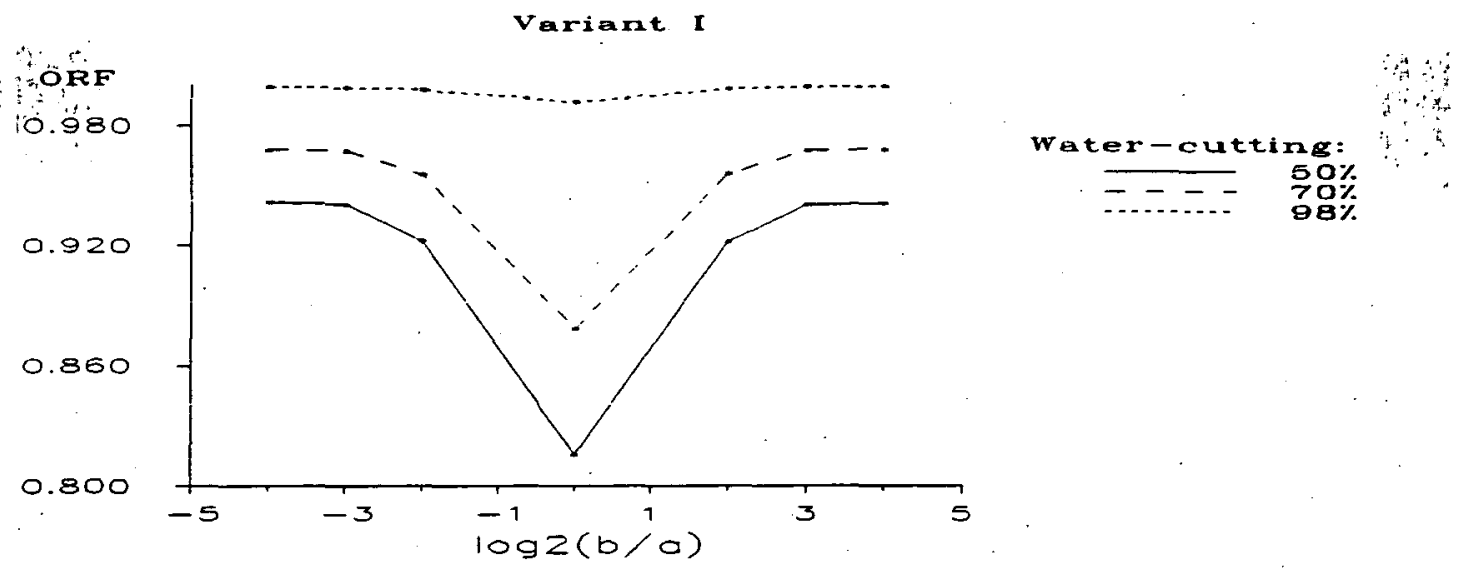

Fig. 7. $\mathrm{ORF}$ as a function of the sides' ratio of five-spot pattern when $\mathrm{Kx} / \mathrm{Ky}=1$.

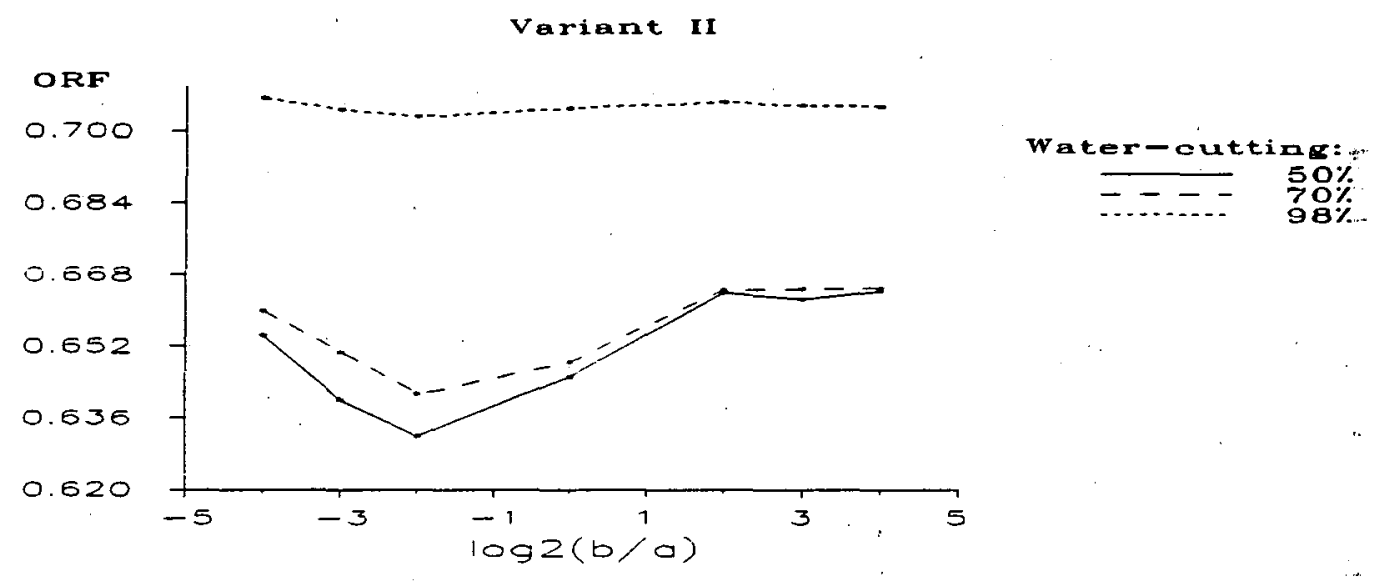

Fig. 8. ORF as a function of the sides' ratio of five-spot pattern when $\mathrm{Kx} / \mathrm{Ky}=10$.

Variant III

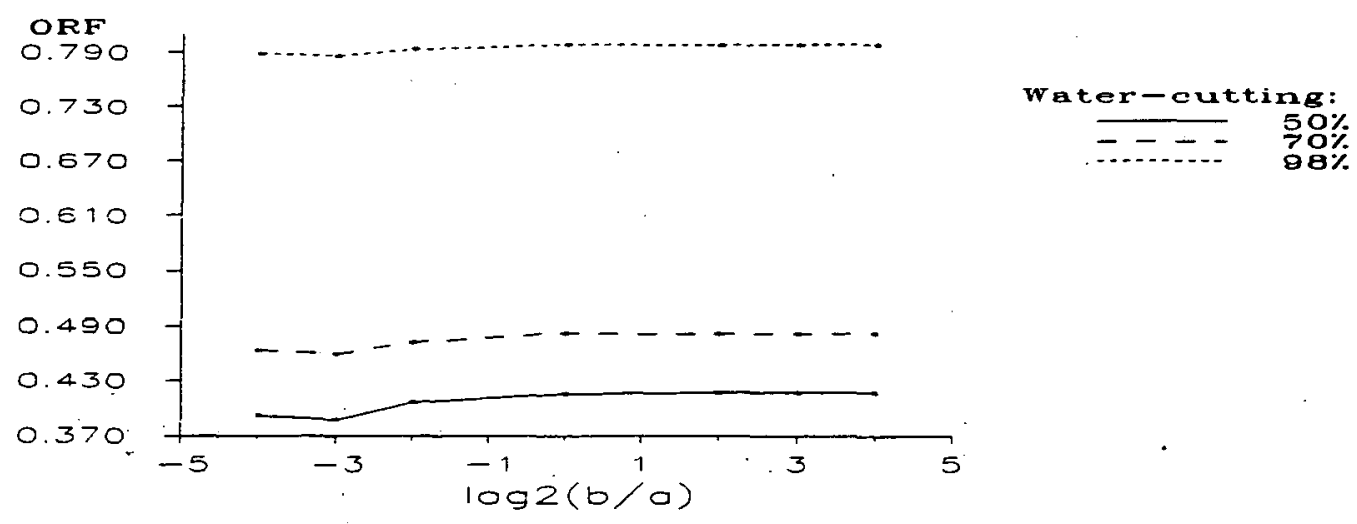

Fig. 9. ORF as a function of the sides' ratio of five-spot pattern at $\mathrm{Kx} / \mathrm{Ky}=100$. 
the ORF increase in both isotropic and anisotropic formations. Optimal well pattern deformation degree could be established as the result of statement and solving of corresponding technic-economic problem, since ORF growth is accompanied by the increase of energetic expenses when we increase the distance between the producing and injection wells.

3. Not all the traditional well patterns are applicable in the case of anisotropic reservoirs. The application of development elements with large number of producing wells per one injector could result in ORF loss expressed in premature water-cutting of some wells. The five-spot well pattern is the least sensitive system from formation anisotropy under high water cutting, if its sides direction coincides with main axes of permeability tensor.

\section{REFERENCES}

1. Romm E.S. Flow properties of fractured rocks. Publ. House Nedra, Moscow, 1966(in Russian).

2. T. D. van Golf-Racht. Fundamentals of fractured reservoir engineering. Elsevier Scientific Publishing Company, 1982.

3. Muskat $\mathrm{M}$. The flow of homogeneous fluids through porous media. I.W. Edwards. Inc. Ann. Arbor, Michigan, 1946.

4. Telkov A.P., Stklyanin Y.I. Water cones forming during oil and gas production. Publ. House Nedra, Moscow, 1965 (in Russian).

5. Kurbanov A.K., Katz R.M., Sherstnyakov V.F., Kundin A.S. Investigation of anisotropy influence on forming cones in oil rims. Proc. of VNII, Publ. House Nedra, Moscow, issue 75, 1981 (in Russian).

6. Romm E.S. Structural models of rock porous media. Publ. House Nedra, Moscow, 1985(in Russian).

7. Clonts M.D., Ramey H.J. Pressure transient analysis for wells with horizontal drainholes. SPE 15116 paper presented at 56th California Regional Meeting of SPE, April 2-4, 1986.

8. Kuchuk F.J., Goode P.A. Brice B.W., Sherrard D.W. Pressure transient analysis and inflow performance for horizontal wells. SPE 18300 paper presented at the 63th Annual Technical Conference and Exhibition of SPE, October 2-5, Houston, 1988.

9. Goode P.A., Wilkinson D.J. Inflow performance of partially open horizontal wells. JPT, No 8, 1991.

10. Peaceman D.W. Representation of a horizontal well in numerical reservoir simulation. SPE 21217 paper presented at the 11 th SPE Symposium on reservoir simulation, Anaheim, Febr, 17-20, 1991.

11. Bear J., Braester C., Menier P.S. Effective and relative permeabilities of anisotropic porous media. Trans. Porous Media, vol. 2, 1987.

12. Dmitriev N.M. Flow in anisotropic reservoirs. Models and effects. Paper presented at International Conference "Gascondensate fields development", 29 May-2 June, Krasnodar, 1990(in Russian).

13. Maksimov V.M., Dmitriev N.M. Simulation of multiphase flow in formation with given anisotropy character. Paper presented at the International Conference "Gascondensate tields development", 29 May - 2 June, Krasnodar, 1990(in Russian).

14. Dmitriev N.M. Maksimov V.M. Darcy's law, phase and relative permeabilities for flow in anisotropic porous media. Proc. of the Conference on the Simulation of flow processes and oil field development. Publ. House of Mechanics and Mechanical Engineering Institute, Kazan, 1992(in Russian).

15. Hirasaki G.J. Pulse tests and other early transient pressure analysis for in-situ estimation of vertical permeability. SPEJ, Feb., 1974.

16. Kamal M.M. Interference and pulse testing - a Review. JPT, vol. 35, No 13, 1983.

17. Head E.L., Bettis F.S. Reservoir anisotropy determination with multiple probe pressures. JPT, No 12, 1993.

18. Ramey H.J. Interference analysis for anisotropic formation - A case history. JPT, No 10, 1975.

19. Nikolaevsky V.N. Convective diffusion in porous media. Appl. Mathem. and Mechan., issue 6, 1959(in Russian).

20. Sokolovsky E.V., Soloviev G.V., Trenchikov Y.J. Indicator methods of oil and gas bearing formations examination. Publ. House Nedra, 1986(in Russian).

21. Schelkachev V.N., Lapuk B.B. Underground hydraulics. Publ. House Gostoptechizdat, Moscow, 1949(in Russian).

22. Muskat M. Physical principles of oil production. McGraw-Hill Book Company Inc., 1949.

23. Krilov A.P., Belash P.M., Borisov Y.P. Design of oil fields development. Publ. House Gostoptechizdat, Moscow, 1962(in Russian).

24. Pilatovsky V.I. Basis of hydromechanics of thin formation. Publ. House Nedra, 1966(in Russian).

25. Sattarov M.M., Kuzilov I.A. Selection of optimal well pattern. Publ. House Bashknigoizdat, Ufa, 1966(in Russian).

26.Djalilov K.N. Problems of water-oil contact movement and well water-cutting. Publ. House ELM, Baku, 1974(in Russian).

27. Lisenko V.D., Muharsky E.D. Design of intensive oil fields development systems. Publ. House Nedra, Moscow, 1975(in Russian).

28. Fazliev R.T. Areal water tlooding. Publ. House Nedra, Moscow, 1979(in Russian).

29. Palatnik B.M., Piskarev V.I. Numerical method for solving the problem of two-phase multidimensional flow in porous media (Paper in publication, in Russian). 